\title{
O financiamento de ações com recursos da cobrança pelo uso da água e a mensuração de seus resultados sobre recuperação e preservação: o caso da bacia hidrográfica do rio Paraíba do Sul
}

\author{
Mariana da Costa Facioli \\ Rua Arquimedes Vigiane Flecher, 80 / apto101 - Resende/RJ \\ marianafacioli@hotmail.com
}

\begin{abstract}
In this proposal we will discuss how to prioritize actions to be financed with funds from charging for the use of water in the basin of the Paraíba do Sul and the results achieved will be measured under the National Policy of Water Resources, highlighting the points most critical to be worked out in the basin both in terms of environmental and institutional and suggesting the establishment of a referential framework of indicators that provide better guidance on the allocation of resources and effective results of the managers responsible. The proposal, more than theoretical-conceptual, has practical applicability to develop, and it will be an important management tool in the process of decision making in this context.
\end{abstract}

Palavras-chave: basin of Paraíba do Sul, National Policy of Water Resources, referencial framework of indicators, effective results, practical appicability, management.

\section{Introdução}

O tema central desta proposta consiste na definição de indicadores de sustentabilidade para a Bacia do Rio Paraíba do Sul, a partir da análise das formas de alocação dos recursos financeiros advindos da cobrança pelo uso da água na bacia, definidas pelo CEIVAP (Comitê de Integração da Bacia Hidrográfica do Rio Paraíba do Sul) e executadas pela AGEVAP e tomadores de recursos. Nesses termos, se estará analisando as prioridades de investimentos ao longo dos últimos anos e a observação sobre sua interferência efetiva na preservação dessa Bacia, tendo em vista as recomendações legais, conforme preconizado no artigo 22 da Lei Federal 9.433/1997, visando à proposição de indicadores de sustentabilidade para esse processo.

\section{Justificativa}

A Gestão dos Recursos Hídricos no Brasil tem sido foco de discussões em diversos âmbitos: governo (federal, estadual e municipal), universidades, usuários e sociedade civil.

Desde a promulgação da Lei Federal 9.433/97, a Lei das Águas, que instituiu a Política Nacional de Recursos Hídricos, os atores envolvidos buscam medidas que possam, efetivamente, aumentar a disponibilidade hídrica, melhorar a qualidade da água e incentivar a racionalização de seu uso.

Dentre os envolvidos nesse processo, estão o Comitê de Bacia Hidrográfica e sua respectiva Agência de Água, cujas previsões legais estão dispostas nos Capítulos III e IV, respectivamente, da lei citada.

O Comitê de Bacia e a entidade delegatária de funções de Agência de Água a serem abordados nesta proposta são o CEIVAP - Comitê para Integração da Bacia Hidrográfica do Rio Paraíba do Sul e a AGEVAP - Associação Pró-Gestão das Águas da Bacia Hidrográfica do Rio Paraíba do Sul que, segundo a Lei 10.881/04 e o Contrato de Gestão que tem com a ANA - Agência Nacional de Águas - desde o ano de 2004, está apta a exercer tais funções.

O CEIVAP foi constituído no ano de 1.996 e a fórmula proposta pelo Comitê para iniciar a cobrança pelo uso da água na Bacia, em rios de domínio da União, foi aprovada pelo CNRH - Conselho Nacional de Recursos Hídricos e teve início em março do ano de 2003. 
A cobrança pelo uso da água começou após a aprovação do Plano de Recursos Hídricos para a Bacia. Este documento, a partir do diagnóstico da Bacia, é o instrumento direcionador das ações a serem adotadas para a gestão. Nesses termos, o repasse dos recursos arrecadados pela ANA é feito anualmente, à AGEVAP cujas atividades-fim, conforme preconiza o Capítulo IV da Lei das Águas, abrangem toda forma de gerenciamento dos recursos da cobrança quanto à sua aplicação, principalmente, em estudos, projetos e obras.

Como forma de destinação destes recursos, o CEIVAP, por meio de deliberação, estabelece a elaboração de um Manual de Investimentos para orientação quanto à aplicação dos recursos arrecadados anualmente. Uma das orientações é quanto ao percentual dos recursos que será destinado a cada tipo de ação: gestão, planejamento e estrutural, considerando o proposto no Plano de Recursos Hídricos da Bacia.

O Manual de Investimentos, elaborado pela AGEVAP com auxílio da Câmara Técnica do Comitê, torna público as condições que as instituições precisam seguir para submeter propostas de projetos que beneficiem a Bacia. As propostas selecionadas recebem recursos financeiros para execução.

As propostas são enviadas à AGEVAP, Secretaria Executiva do CEIVAP, para análise das viabilidades institucional, fiscal, jurídica e técnica. Quando da conclusão, são emitidos relatórios e laudos indicando os projetos e obras passíveis de financiamento.

A relação das propostas habilitadas é encaminhada ao Comitê, que define as prioridades que receberão recursos financeiros, considerando as proposições técnicas do Plano de Recursos Hídricos e as articulações políticas vigentes. Definidos os projetos e obras a serem contemplados é feito um contrato de repasse entre a AGEVAP e a "instituição tomadora de recursos", com a interveniência da Caixa Econômica Federal que acompanha a execução dos mesmos, conforme priorização do Comitê. Neste processo a AGEVAP, com o auxílio da fiscalização da Caixa Econômica Federal, acompanha a execução dos contratos e realiza repasses dos valores previstos nos projetos. Atualmente, no biênio 2009/2011, o CEIVAP conta com sessenta membros, sendo: vinte e três representantes do poder público (União: 3, Minas Gerais: 7, Rio de Janeiro: 7, São Paulo: 6), vinte e quatro usuários (Minas Gerais: 8, Rio de Janeiro: 8, São Paulo: 8) e treze representantes da sociedade civil ((Minas Gerais: 4, Rio de Janeiro: 4, São Paulo: 5).

$\mathrm{O}$ valor médio anual repassado da ANA à AGEVAP é de R 8 milhões de reais e, na atualidade, o foco principal que norteia as ações da ANA, CEIVAP e AGEVAP é a redução da carga orgânica, apontado no Plano de Recursos Hídricos da Bacia em vigor (2007 a 2010) como principal fonte poluidora. Segundo o referido Plano, o valor estimado a ser investido para essa redução deverá ser de aproximadamente $R \$ 4$ bilhões de reais, o que sugere a imediata necessidade de avaliar o quanto às ações desenvolvidas até o momento contribuem para atingir a meta proposta. Desse modo é importante definir indicadores para que o Sistema CEIVAP/AGEVAP consiga melhor orientar a alocação dos recursos disponíveis de modo a atender às proposições do Plano de Recursos Hídricos da Bacia em vigor e, com isso, contribuir para a melhoria da qualidade e disponibilidade hídrica da Bacia do Rio Paraíba do Sul.

\section{Contextualização da problemática}

Para melhor entendimento sobre a complexidade dos processos socioambientais da Bacia do Rio Paraíba do Sul é fundamental a observância quanto à sua organização e dinâmica, que se caracteriza pela disputa entre formas diferenciadas de uso e gestão dos recursos naturais e territoriais ali disponíveis e se reflete nas atuais condições de sustentabilidade ambiental da bacia. 
O território da Bacia do rio Paraíba do Sul abrange três estados da Região Sudeste - São Paulo (13.500 km²), Rio de Janeiro $\left(21.000 \mathrm{~km}^{2}\right)$ e Minas Gerais $\left(20.900 \mathrm{~km}^{2}\right)$. A Bacia do rio Paraíba do Sul abrigava no ano 2000, 4.920 .915 habitantes (IBGE, Censo 2000) e, em 2005, 5.254.360habitantes (IBGE, população estimada), distribuídos em 180 municípios: 88 municípios em Minas Gerais, 53 municípios no Rio de Janeiro e 39 municípios em São Paulo. O estado do Rio de Janeiro é o que abriga o maior contingente populacional da bacia, sem contar a sua importância para o abastecimento da capital do Rio de Janeiro, devido à transposição de dois terços de suas águas para o rio Guandu.

Em linhas gerais, algumas características se destacam:

- O trecho da bacia referente a maioria dos municípios paulistas e do sul fluminense é o mais industrializado e urbanizado;

- Sob as óticas da demografia e da economia, trata-se do principal e mais denso eixo de desenvolvimento do país onde predomina, como característica principal, a condição de território intensamente urbanizado;

- O Vale do Rio Paraíba do Sul é uma importante região turística, com destaque para Vassouras, com influência cafeeira e para o Parque Nacional de Itatiaia, o primeiro do Brasil; - A dinâmica territorial da porção mineira da bacia do rio Paraíba do Sul é marcada pela dificuldade de ampliação das funções urbanas, e da pequena integração produtiva e comercial entre as suas economias.

Nesses termos, as mesmas riquezas naturais que atraíram e facilitaram a ocupação no território da bacia do Paraíba do Sul e bacias afluentes que a compõe, foram esgotadas continuamente no início do processo de ocupação com desdobramentos observados até os dias de hoje. Para compreender melhor essa dinâmica, há de se considerar aspectos como: o caráter antigo de sua ocupação; a alta densidade demográfica, a ocorrência do maior índice de população urbana do país e o elevado grau de industrialização de trechos como as regiões do Médio Paraíba do Sul e do Vale do Paraíba do Sul paulista. Podem ser citados como os principais usos e demandas hídricas na bacia do Paraíba do Sul: o consumo doméstico, industrial, agropecuário e para fins hidroelétricos.

Outro aspecto a ser considerado refere-se à condição do rio Paraíba do Sul e seus afluentes como receptor dos efluentes produzidos na bacia, que é o fator de maior relevância atualmente tanto para o Plano de Recursos Hídricos da Bacia como para o Contrato de Gestão firmado entre ANA e AGEVAP. Com a ausência de tratamento dos esgotos domésticos na maioria das cidades as condições ambientais e de saúde pública deixam a desejar. Soma-se a essa situação outro problema presente na bacia: a poluição industrial que provoca a contaminação das águas.

Com relação aos principais problemas da Bacia do Rio Paraíba do Sul, merecem destaque: falta de saneamento e poluição hídrica; descarte de resíduos industriais; contaminação de mananciais de abastecimento por defensivos agrícolas (decorre da atividade mineradora); ocupação irregular e desordenada da calha do rio Paraíba do Sul nas cidades ribeirinhas e a conseqüente degradação da mata ciliar, fundamental para o não assoreamento do rio; problemas nos canais de Campos dos Goytacazes; impactos e conflitos decorrentes da transposição de dois terços das águas do rio Paraíba do Sul para o rio Guandu.

Há interesse, nesse momento, em salientar a importância dessas ocorrências como referência para a identificação dos principais conflitos de uso na bacia e seus rebatimentos nas propostas de uso dos recursos financeiros disponíveis para sua recuperação e preservação, o que gera o desafio de se investir na definição de indicadores de sustentabilidade que possam orientar a escolha das melhores opções de projetos para a alocação dos referidos recursos e o aferimento da efetividade destes. 


\section{Referencial teórico básico}

As noções de sustentabilidade, condições de vida e conflitos orientam as reflexões aqui propostas. Inicialmente tem-se que a noção de conflito aqui utilizada é aquela que traduz as representações das formas pelas quais os homens relacionam-se entre si, com o território e com os recursos naturais nele disponíveis.

Nessa perspectiva, o "conflito" é o elemento que auxilia a compreensão de como se organiza o território da bacia do Rio Paraíba do Sul, quais suas áreas vulneráveis, como ocorrem as diferentes formas de apropriação, uso e gestão dos recursos hídricos disponíveis; como essas formas concorrem entre si, como os sujeitos sociais se organizam em torno delas e, principalmente, quais suas "razões" e funcionalidade. Ou seja, para as reflexões aqui apresentadas, o "conflito" é também um instrumento de leitura do social, uma vez que permite compreender como o território tende a ser esquadrinhado em função de interesses diversos e ou de sensibilidades variadas.

Ao falarmos de conflitos pelas formas de apropriação, uso e gestão dos recursos hídricos se está tratando, simultaneamente, de conflitos sociais e ambientais. A existência de conflitos ambientais é dada pela ocorrência de disputas entre as diferentes visões de mundo existentes no espaço social; concepções ancoradas em representações e simbolizações diferenciadas sobre Sociedade e Natureza. Nesses termos, a noção de conflito é estruturante, pois decorre das diferentes maneiras pelas quais os sujeitos representam simbolicamente o modo como usam e se apropriam de territórios e de seus recursos naturais. Isto se deve ao fato de que detrás da idéia de natureza ocorrem lutas e disputas expressivas de relações de domínio, pois se trata de uma natureza transformada e apropriada pela ação humana.

Dessa forma, a noção de meio ambiente, ao falar de recursos que são apropriados e transformados, expressa também os processos que envolvem disputas dos homens entre si e representações. Na realidade, a noção de ambiental é construída no interior de um processo de luta e de constituição dos sujeitos políticos, tendo como base de referência os contextos sócioculturais específicos, nos quais essas lutas se instauram. Isso indica que o discurso ambiental (ou os discursos ambientais) é, com certeza, um discurso mutante, pois evocam representações diferenciadas, visões de mundo diferentes. Logo, somente conhecendo a sua diversidade (que está associada a práticas e disputas), é possível apreender o seu sentido.

No caso do gerenciamento da bacia do rio Paraíba do Sul os conflitos revelam a presença de atores diversos, diferenciados segundo sua posição no contexto do Comitê de Bacia, onde existem as representações institucionais que lutam pela construção e apropriação simbólica de poder, levando em conta uma rede de relações formada por empresas, entidades da sociedade civil e poder público da bacia e das bacias afluentes.

No Comitê de Bacia há de se conciliar os interesses dos representados, as disputas, as negociações engendradas e a formação dos centros de decisão com as formas de pressão sobre a bacia do rio Paraíba do Sul e o viés técnico necessário para a gestão a fim de cumprir o proposto no Plano de Recursos Hídricos para a recuperação e preservação dos recursos naturais. Essa contradição sugere que o tema "meio ambiente" tende a mobilizar diferentes concepções e permite a observação do delineamento de um campo de disputas, conflitos e alianças. Como a noção de conflito é, por vezes, muito abrangente os aspectos ambientais tendem a ser prioritários, sobretudo, quando do estudo de bacias.

A Lei 9.433, que institui a Política Nacional de Recursos Hídricos, ao definir como um de seus princípios fundamentais o uso múltiplo da água, admite que, com a escassez desses recursos, os diferentes usos podem ser conflitantes entre si. Além disso, a organização e vitalização dos Comitês de Bacias Hidrográficas impõem a participação de toda sociedade. Esta situação por si só evidencia a configuração de um "Campo" de interesses e, 
conseqüentemente de disputas que, eventualmente, podem ser arbitradas pelas instâncias públicas (exemplo: Agência Nacional de Águas - ANA), mas ainda assim decorrem das pressões gestadas na sociedade.

No que se refere às noções de sustentabilidade e qualidade vida como referência para a formulação de indicadores tem-se que um indicador é uma medida, em geral quantitativa, portadora de significado que oferece parâmetros orientadores das ações de planejamento e gestão. Nesses termos, o indicador finda por ser um elo entre metas a serem adotadas e a realidade que se pretende mensurar e controlar. Nesses termos, a definição de indicadores que possam auxiliar na avaliação de condições de sustentabilidade da bacia estudada e definir parâmetros para a qualidade de vida de suas populações passa necessariamente pelo reconhecimento de que se estará lidando com representações a cerca das formas de uso e gestão dos recursos naturais e territoriais ali disponíveis e que essas representações estão situadas num campo onde prevalecem as disputas e confrontos.

Assim o desafio teórico e conceitual dessa proposta de pesquisa consiste também em trabalhar com esse confronto de representações para avaliar quais podem ser os parâmetros comuns que oferecem e tornam possível a definição de indicadores que possam orientar as escolhas dos "melhores" ou "mais adequados" projetos para a Bacia do rio Paraíba do Sul, bem como medir a efetividade das ações.

\section{Indicações metodológicas}

A metodologia proposta para este trabalho está estreitamente vinculada aos objetivos que pretendem ser alcançados ao longo de seu desenvolvimento. Em linhas gerais, os procedimentos metodológicos adotados podem ser enunciados nos seguintes termos:

- Revisão teórica e conceitual e levantamento da base de dados secundários a ser trabalhada (caracterização da bacia, representações em disputa e parâmetros de avaliação);

- Revisão da literatura referente a indicadores e avaliação da possibilidade de indicadores como instrumento de planejamento e gestão de bacia;

- Relacionar as metas do Plano de Recursos Hídricos da Bacia do Rio Paraíba do Sul (PRHPS) por área de atuação dos organismos de bacia (sete áreas) para que possa ser feito um trabalho de conscientização quanto às necessidades de ações a serem financiadas em cada região. Partindo deste princípio, deverá haver um estreitamento no relacionamento do Comitê Federal - CEIVAP - com os Comitês de Bacias Afluentes, de modo que o CEIVAP haja em parceria com as entidades da organização civil organizada da bacia, visando o atingimento das metas constantes do Plano;

- Levantamento de dados sobre o processo de financiamento de ações com recursos da cobrança: desde os indicadores propostos pelo Contrato de Gestão firmado entre ANA e AGEVAP até o acompanhamento, pela AGEVAP, da execução das ações, relacionando os projetos e obras hierarquizadas pelo CEIVAP, por área de abrangência, segundo o Plano de Bacia, e respectivos valores. Verificar quais projetos foram concluídos, cancelados, estão vigentes e quanto representam do total a ser investido em sua área (consultar os Cadernos das regiões dos sete organismos de bacia constantes do Plano de Bacia);

- Análise do Manual de Investimentos e dos laudos de aprovação de projetos - observação da correlação entre recomendações no Manual e os referidos laudos;

- Relacionar, em ordem seqüencial, como funciona atualmente o processo de hierarquização das propostas a serem contempladas com recursos da cobrança e identificar, em cada uma das etapas, o que poderia ocorrer para melhoria do processo, como: oficinas de incentivo à elaboração de projetos condizentes com as prioridades do Plano da Bacia, utilização de critérios cada vez mais técnicos e menos políticos para elaboração de manuais de investimentos e priorização de projetos, mobilização de forças políticas para alavancagem 
de recursos extra-cobrança como forma de ampliar os investimentos na bacia, já que o valor arrecadado anualmente é insuficiente para suprir à demanda das ações necessárias para recuperação e preservação dos recursos hídricos, entre outros.

- Proposição de um quadro referencial de indicadores.

\section{Referências bibliográficas}

AGEVAP. Associação Pró-Gestão das Águas da Bacia Hidrográfica do Rio Paraíba do Sul. Bacia do Rio Paraíba do Sul. Estudo e Publicações. CAMPOS, Jander Duarte; AZEVEDO, José Paulo Soares; MAGALHÃES, Paulo Canedo. Cobrança pelo uso da água nas transposições da bacia do rio Paraíba do Sul. XV Simpósio Brasileiro de Recursos Hídricos, 2003. Disponível em: <http://ceivap.org.br/gestao_4.php>. Acesso em: 2009.

AGEVAP. Associação Pró-Gestão das Águas da Bacia Hidrográfica do Rio Paraíba do Sul. Gestão da Bacia. Contrato de Gestão ANA-AGEVAP. Brasília, 2004. Disponível em: <http://ceivap.org.br/gestao_4.php>. Acesso em: 2009.

AGEVAP. Associação Pró-Gestão das Águas da Bacia Hidrográfica do Rio Paraíba do Sul. CASTOR, Belmiro Valverde Jobim; COSTA, Francisco José Lobato. Planejamento Estratégico. Rio de Janeiro, 2007. Disponível em: < http://ceivap.org.br/saibamais13.php>. Acesso em: 2009.

AGEVAP. Associação Pró-Gestão das Águas da Bacia Hidrográfica do Rio Paraíba do Sul. Plano da Bacia do Rio Paraíba do Sul. Plano de Recursos Hídricos da Bacia do Rio Paraíba do Sul. Rio de Janeiro, 2007. v. 1. Disponível em: <http://ceivap.org.br/gestao_2.php>. Acesso em: 2009.

COSTA, Francisco José Lobato. Estratégias de Gerenciamento de Recursos Hídricos no Brasil: Áreas de Cooperação com o Banco Mundial. $1^{a}$ ed. Brasília: Banco Mundial, 2003. 204 p.

GRANZIERA, Maria Luíza Machado. Direito de Águas: disciplina jurídica das águas doces. 1 ed. São Paulo: Atlas, 2001. p. 218-225.

MACHADO, Paulo Afonso. Recursos Hídricos: direito brasileiro e internacional. 1 ed. São Paulo: Malheiros Editores, 2002. p. 78-122.

MOTTA, Ronaldo Serôa. Economia Ambiental. 1 ed. Rio de Janeiro: Editora FGV, 2006. p. 9-22; 107-131.

PROJETO MARCA D’ÁGUA: Seguindo as mudanças na gestão das bacias hidrográficas do Brasil. Caderno 2: Comitês de Bacia sob o olhar dos seus membros. Organização: Beate Frank. Blumenau: FURB, 2008. 54 p.

SERRICHIO, Claudio; CALAES, Virgínia; FORMIGA-JOHNSSON, Rosa Maria; LIMA, Ângelo José Rodrigues; ANDRADE, Edilson de Paula. Prêmio CAIXA em melhores práticas de gestão local 2003/2004. O CEIVAP e a gestão integrada dos recursos hídricos da bacia do rio Paraíba do Sul: Um relato da prática. Coordenação: Rosa Maria Formiga Johnsson. Rio de Janeiro: CAIXA, 2005. 127 p. 